\title{
Fine needle aspiration cytology diagnosis of caesarean scar endometriosis with histopathological correlation: a case report
}

\author{
Sandeep P. Kumar*, Varuna Mallya, Krishna Kishor
}

Department of Pathology, Dr. B.R. Ambedkar Medical College, K.G. Halli, Bengaluru-560045, Karnataka, India

Received: 09 April 2015

Accepted: 09 May 2015

\section{*Correspondence:}

Dr. Sandeep P. Kumar,

E-mail: drsandeepkumarp@gmail.com

Copyright: $\odot$ the author(s), publisher and licensee Medip Academy. This is an open-access article distributed under the terms of the Creative Commons Attribution Non-Commercial License, which permits unrestricted non-commercial use, distribution, and reproduction in any medium, provided the original work is properly cited.

\begin{abstract}
Endometriosis is defined as the presence of endometrial tissue outside the endometrium or myometrium. It occurs in $8-15 \%$ of women of reproductive age group with abdominal wall endometriosis accounting for only $0.5-1 \%$ of all pelvic endometriosis. We present a case of a 25 year old lady who presented with a mass in the anterior abdominal wall over a previous caesarean section scar. Endometriosis was diagnosed on Fine Needle Aspiration Cytology (FNAC) based on the findings of monolayered sheets of endometrial cells, few spindle shaped stromal cells and hemosiderin laden macrophages in the background. Histopathological examination confirmed the cytological diagnosis. Endometriosis in scar tissue is a rare disease which might be difficult to diagnose and should always be considered in evaluation of painful abdominal masses in women. Fine needle aspiration cytology is economical, fast and accurate method to make the diagnosis of scar endometriosis and to plan better surgical approach.
\end{abstract}

Keywords: Caesarean scar endometriosis, Fine needle aspiration cytology, Endometriosis

\section{INTRODUCTION}

Endometriosis is defined as the presence of endometrial tissue outside the endometrium or myometrium. Usually both epithelium and stroma are seen, but occasionally the diagnosis of endometriosis can be made when only one component is present. ${ }^{1}$ It occurs in $8-15 \%$ of women of reproductive age group. It can involve a variety of extrauterine locations - both genital and extra-genital. Extra-genital endometriosis can be seen in such varied locations as intestines, lungs, pleura, kidneys and surgical scars. Cutaneous endometriosis is usually seen in abdominal scars following obstetric or gynaecologic surgery. Surgical scar endometriosis following cesarean section has an incidence of $0.03 \%-0.4 \%$. It can be clinically confused with abscess, suture granuloma, hematoma, desmoid tumor, or primary and metastatic cancer. $^{2}$
We hereby report a case of scar endometriosis, clinically mistaken for an abscess, which was diagnosed on fine needle aspiration cytology and subsequently confirmed by histopathological examination. There are very few cases of endometriosis diagnosed by FNAC and hence we present our findings in order to further enhance the understanding of cytological findings of endometriosis.

\section{CASE REPORT}

A 25 year old lady presented with history of swelling in the lower abdominal wall since 2 years. The patient was referred for FNAC with a clinical diagnosis of abscess. She gave a history of pain over the swelling which increased during menstruation. The patient had undergone caesarean section two and a half years back. On examination, a solitary mass was noted in the lower abdominal wall over the caesarean section scar. The mass 
measured $2 \times 2 \mathrm{~cm}$ in size, was hard in consistency, immobile and tender on palpation.

Fine needle aspiration cytology showed cellular smears composed of mono-layered sheets of round to oval cells having moderate amount of cytoplasm and round to oval bland nuclei with moulding of nuclei. Also seen were many spindle shaped cells admixed with the above mentioned epithelial cells in the background of apoptotic debris, numerous hemosiderin laden macrophages and hemorrhage (Figure 1). Based on the above findings and clinical history, a diagnosis of endometriosis was made.

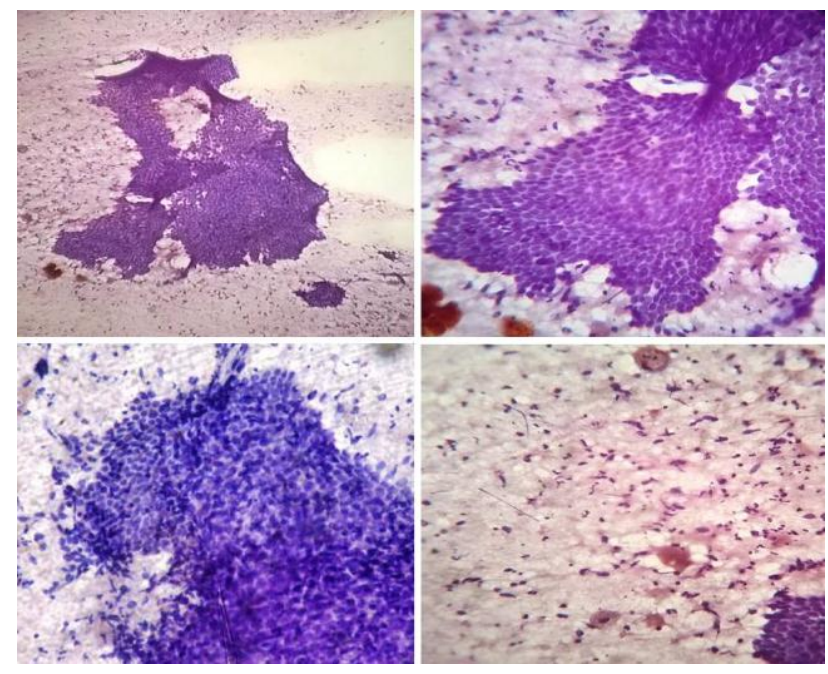

Figure 1: (a) Shows endometrial cells in the monolayered sheets (H\&E, x100). (b), (c) Shows endometrial cells in monolayered sheets with a few spindle shaped cells in the background (H\&E, Pap, x400). (d) Shows a few scattered hemosiderin laden macrophages (H\&E, x400).

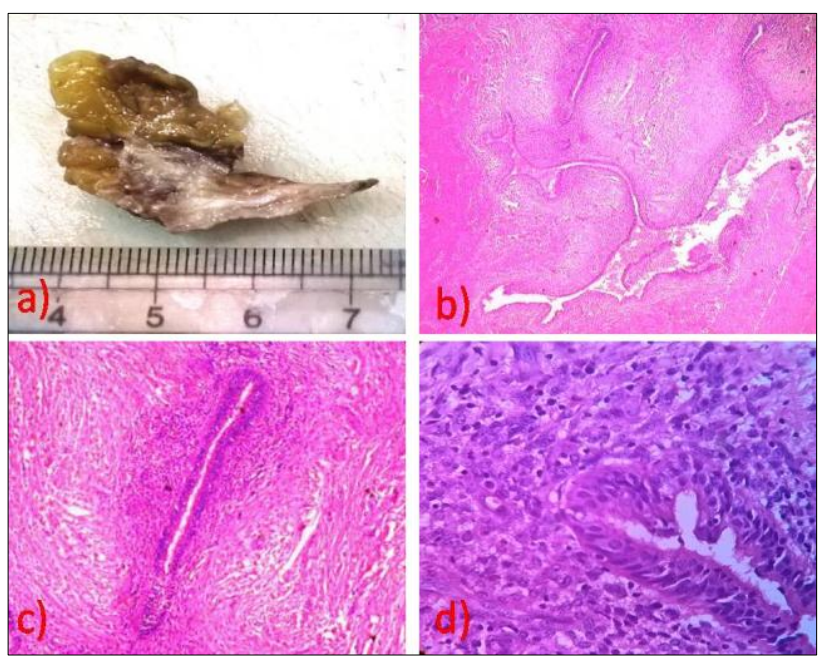

Figure 2: (a) Shows the gross specimen measuring $3 \times 3$ cm with grey brown areas on cut section. (b), (c), (d) Shows endometrial glands embedded in fibrocollagenous tissue with surrounding endometrial stroma (H\&E x40, x100, x400).
The mass was excised with a margin of $1 \mathrm{~cm}$ all around and sent in $10 \%$ formalin for histopathological examination. Gross examination revealed a single greybrown to yellow tissue mass measuring $3 \times 3 \mathrm{~cm}$. Cut section showed brownish areas. Microscopy revealed endometrial glands embedded in fibrocollagenous tissue. The glands were lined by columnar epithelium with stratification at places. Endometrial stroma was seen surrounding the glands (Figure 2).

\section{DISCUSSION}

Endometriosis refers to functional endometrial glands and stroma lying outside the uterine cavity. Endometriosis occurring in a surgical scar is called incisional endometriosis or scar endometriosis. ${ }^{3}$

The first case of scar endometriosis was reported by Meyer in $1903 .{ }^{4}$ Blanco et al. reported 12 cases of scar endometriosis. All patients had a history of gynecologic operations and presented, after an average of 1.9 years, with a tender mass (average $4 \mathrm{~cm}$ ) at the previous incision site. ${ }^{5}$ In a study by Pathan et al., seven cases occurred in caesarean and one occurred in a hysterectomy scar. ${ }^{6}$ Horton et al. reviewed 445 cases of abdominal wall endometriosis among which 57\%,11\% and $12 \%$ cases occurred in scars of caesarean section, hysterectomy and other surgical procedures, respectively. ${ }^{7}$ Our patient also gave a history of a tender swelling in the anterior abdominal wall after having undergone a caesarean section two and a half years ago.

Several theories have been proposed for the pathogenesis of endometriosis: implantation theory, direct extension theory, coelomic metaplasia theory (metaplasia of the peritoneum), induction theory, lymphatic and vascular metastasis theory and composite theory. ${ }^{4}$ Most favored hypotheses are implantation and induction theories for abdominal scar endometriosis. In induction theory, the chemical substances elaborated by the sloughed endometrium can induce the formation of endometriosis, though the viability of the sloughed material is not a requirement. In implantation theory, the viability and ability of the sloughed endometrium to implant is important. This theory is supported by a greater frequency of endometriosis after abdominal hysterotomy than cesarean section, suggesting that the late pregnancy deciduas has a lower ability to implant. ${ }^{8}$

Various non-invasive diagnostic imaging modalities like USG with colour Doppler, CT scan and MRI are able to give correct diagnosis but lack specificity. ${ }^{9}$

In clinically doubtful cases, FNAC can be a valuable diagnostic tool. Cytology smears show sheets of epithelial cells, spindled stromal cells and a variable number of hemosiderin laden macrophages. The stromal cells are plump, spindled and arranged around a vascular meshwork. The presence of any two of the three components is required for the diagnosis of endometriosis. ${ }^{3}$ Monolayered sheets of round to oval cells 
with moderate amount of cytoplasm admixed with spindle shaped cells and hemosiderin laden macrophages was seen in our smears. The importance of FNAC lies in excluding other lesions like abscess, suture granuloma, hematoma, desmoid tumor, or primary and metastatic cancer. Absence of inflammatory cells, foreign body granulomas, clusters of spindle cells and atypical or neoplastic cells in our smears ruled out the above mentioned possibilities.

Medical management with oral contraceptive pill, progestogens and gonadotropin releasing hormone analogues provide alleviation of symptoms, but recurrence after cessation of therapy is common. Wide surgical excision with at least $1 \mathrm{~cm}$ margin on all sides is the treatment of choice. ${ }^{10}$

\section{CONCLUSION}

Endometriosis in scar tissue is a rare disease and hence we present this case to reiterate the need to consider endometriosis in evaluation of painful abdominal masses in women. Fine needle aspiration cytology is economical, fast and accurate method to make the diagnosis of scar endometriosis and to plan better surgical approach. Owing to its rarity and relatively few cases reported in literature, more cases of scar endometriosis diagnosed by FNAC are necessary to confirm its usefulness as a definitive diagnostic modality.

Funding: No funding sources Conflict of interest: None declared

Ethical approval: Not required

\section{REFERENCES}

1. Philip BC, Robert HY. The peritoneum. In: Stacey EM, Daryll C, Joel KG, Victor ER, Mark HS, eds. Sternberg's Diagnostic Surgical Pathology. 5th ed.
Philadelphia: Lippincott Williams and Wilkins; 2010: 2392-2418.

2. Sengul I, Sengul D, Kahyaoglu S, Kahyaoglu I. Incisional endometriosis: a report of 3 cases. Can J Surg. 2009;52(5):444-5.

3. Veda P, Srinivasaiah M. Incisional endometriosis: Diagnosed by fine needle aspiration cytology. J Lab Physicians. 2010;2:117-20.

4. Agarwal N, Subramanian A. Endometriosis morphology, clinical presentations and molecular pathology. J Lab Physicians. 2010;2(1):1-9.

5. Blanco RG, Parithivel VS, Shah AK, Gumbs MA, Schein M, Gerst PH. Abdominal wall endometriomas. Am J Surg. 2003;185:596-8.

6. Pathan SK, Kapila K, Haji BE, Mallik MK, AlAnsary TA, George SS, et al. Cytomorphological spectrum in scar endometriosis: a study of eight cases. Cytopathology. 2005;16:94-9.

7. Horton JD, Dezee KJ, Ahnfeldt EP, Wagner M. Abdominal wall endometriosis: a surgeon's perspective and review of 445 cases. Am J Surg. 2008;196:207-12.

8. Mahesh KU, Anil KS, Jaya M. Cytological diagnosis of abdominal scar endometriosis. Asian J Med Clin Sci. 2012;1:47-8.

9. Giampiero F, Cristiano G, Giovanni A, Stefano C, Raffaele F, Giampado T. Abdominal wall endometriomas near cesarean delivery scars: sonographic and color Doppler findings in a series of 12 patients. J Ultrasound Med. 2003;22:1041-7.

10. Teng CC, Yang HM, Chen KF, Yang CJ, Chen LS, Kuo CL. Abdominal wall endometriosis: an overlooked but possibly preventable complication. Taiwan J Obstet Gynecol. 2008;47:42-8.

DOI: $10.18203 / 2320-1770 . i j \mathrm{rcog} 20150130$

Cite this article as: Kumar SP, Mallya V, Kishor K. Fine needle aspiration cytology diagnosis of caesarean scar endometriosis with histopathological correlation: a case report. Int J Reprod Contracept Obstet Gynecol 2015;4:921-3. 